\title{
Nebulised salbutamol without oxygen in severe acute asthma: how effective and how safe?
}

\author{
JG DOUGLAS, P RAFFERTY, RJ FERGUSSON, RJ PRESCOTT, GK CROMPTON, \\ IWB GRANT
}

\author{
From the Respiratory Unit, Northern General Hospital, Edinburgh, and the Department of Medical \\ Computing and Statistics, University of Edinburgh
}

\begin{abstract}
Thirty two patients with severe acute asthma, all of whom were hypoxaemic, entered a double blind comparative assessment of three doses of salbutamol $(1.25,2.5$, and $5 \mathrm{mg}$ ) nebulised by an electrically operated air compressor. The study lasted for two hours, during which oxygen and corticosteroid treatment were withheld. All patients were observed in an intensive care area during this period. Four patients had to be withdrawn from the study. Two became distressed immediately after receiving salbutamol and were excluded from further analysis. Two other patients were withdrawn, one with persistent respiratory distress and an unchanged one second forced expiratory volume $\left(\mathrm{FEV}_{1}\right)$ and the other because of the development of profound hypoxaemia and a deteriorating $\mathrm{FEV}_{1}$ within 60 minutes of treatment. No significant differences were observed between the three dosage groups. In the 28 patients completing the study there were only small increases in mean FEV $(0.8$ to $1.1 \mathrm{l})$ and forced vital capacity (FVC) (1.3 to $1.8 \mathrm{l})$ over the two hours. There was a fall in the mean pulse rate at 120 minutes of 15 beats per minute (117-102). No significant change in oxygen tension $\left(\mathrm{PaO}_{2}\right)$ was observed at 15 or 60 minutes after administration of nebulised salbutamol in any of the three groups. Salbutamol nebulised in air, in a single dose of $5 \mathrm{mg}$, produces only slight relief of airflow obstruction and no worsening of hypoxaemia in severe acute asthma.
\end{abstract}

Nebuliser systems driven by electrically operated air compressors are being increasingly used in the treatment of asthma. These devices, which can deliver large doses of bronchodilator drugs in air, have been available in most hospitals for some years; used in conjunction with oxygen treatment, as they usually are, they appear to be both effective and safe in the treatment of severe acute asthma. In the home, however, nebulisers are almost invariably used without access to oxygen treatment. Because of the assumption that the inhalation of large amounts of nebulised bronchodilator solution such as $0.5 \%$ salbutamol may be dangerous in these circumstances, and because some patients may be prodigal in their use of these solutions, a single dose preparation of $2.5 \mathrm{mg}$ salbutamol in $2.5 \mathrm{ml}$ buffered normal saline (Ventolin Nebule) has recently been introduced for use with nebuliser systems. Little is

Address for reprint requests: Dr JG Douglas, City Hospital, Edinburgh EH10 5SB.

Accepted 23 October 1984 known, however, of the efficacy and safety of this preparation in patients with severe acute asthma. In an attempt to determine whether the dose delivered is too large or too small, doses of salbutamol equivalent to a half, one and two Ventolin Nebules nebulised by an air compressor were compared in patients with severe acute asthma.

\section{Methods}

Thirty two patients presenting to hospital with severe acute asthma were studied. None was under 16 years of age, pregnant, or suffering from cardiovascular disease; and all were known to have reversible airflow obstruction in that the one second forced expiratory volume $\left(\mathrm{FEV}_{1}\right)$ had previously been observed to increase by $20 \%$ after the inhalation of $200 \mu \mathrm{g}$ salbutamol aerosol by metered dose inhaler. On entry 31 of the 32 patients had an FEV, of less than $40 \%$ of the predicted normal value. None had been given oxygen within 30 minutes of starting the trial and all had arterial hypoxaemia, 
with a partial pressure of oxygen $\left(\mathrm{PaO}_{2}\right)$ of $7-10 \mathrm{kPa}$ $(52.5-75 \mathrm{~mm} \mathrm{Hg})$ breathing air. Any treatment given within six hours of admission to hospital was recorded. The aims of the study were explained and written informed consent was obtained in each case.

A double blind comparative assessment was performed with three doses of salbutamol $(1.25 \mathrm{mg}, 2.5$ $\mathrm{mg}$, and $5 \mathrm{mg}$ ) dissolved in $2.5 \mathrm{ml}$ buffered normal saline (pH 3.5) and inhaled in the form of an aerosol in air. Ten solutions of each of the three doses were preprepared by the hospital pharmacist, who randomly numbered them $0-30$. The treatments were then used in numerical order. Each dose was placed in a Turret nebuliser attached to a Medix Minor II air compressor. This compressor produces a pressure of $68 \mathrm{kPa}\left(10 \mathrm{lb} / \mathrm{in}^{2}\right)$ and generates a flow rate of $101 \mathrm{~min}^{-1}$. The aerosol was inhaled until nebulisation ceased, which took about seven minutes, and each patient was then observed by experienced medical and nursing staff in an intensive care area for two hours, during which time no other treatment, including oxygen, was given unless this was considered to be necessary on clinical grounds.

$\mathrm{FEV}_{1}$, forced vital capacity (FVC), and pulse rate were recorded before the administration of nebulised salbutamol and at 5, 10, 20, 30, 40, 50, 60, 90, and 120 minutes after salbutamol inhalation. Arterial blood gas analysis was performed before treatment and at 15 and 60 minutes thereafter. Patients were asked to report any adverse effects.

Analysis of variance was used to compare the three treatment groups; linear regression analyses were used to examine the relationships between changes in $\mathrm{FEV}_{1}, \mathrm{FVC}, \mathrm{PaO}_{2}$, and pulse rate; and the correlation coefficient was used to test the association between the initial FEV, and FVC and the changes over two hours.

\section{Results}

All 30 patients had taken salbutamol or terbutaline

Table 1 Mean values for age and initial respiratory values and pulse rate in the 10 patients (standard deviations in parentheses)

\begin{tabular}{lccc}
\hline & \multicolumn{4}{c}{ Dose of nebulised salbutamol } \\
\cline { 2 - 4 } & $1.25 \mathrm{mg}$ & $2.5 \mathrm{mg}$ & $5 \mathrm{mg}$ \\
\hline Age (y) & $37.8(18.1)$ & $33.7(16.3)$ & $40.6(18.0)$ \\
Sex (M:F) & $5: 5$ & $0: 10$ & $4: 6$ \\
FEV (1) & $0.8(0.3)$ & $0.9(0.4)$ & $0.7(0.2)$ \\
FVC (1) & $1.3(0.9)$ & $1.4(0.5)$ & $1.3(0.4)$ \\
Pulse rate & & & \\
$\quad$ (beats/min) & $117.8(13.3)$ & $123.6(19.8)$ & $110.9(23.6)$ \\
Pao $_{2}(\mathrm{kPa})$ & $8.42(0.83)$ & $8.46(0.98)$ & $8.37(1.0)$ \\
\hline FEV & \multicolumn{4}{c}{ Fene second forced expiratory volume; FVC-forced vital } \\
capacity; $\mathrm{PaO}_{2}$-arterial oxygen tension.
\end{tabular}

by metered dose inhaler before arrival in hospital in various doses - up to $2.2 \mathrm{mg}$ for salbutamol and 2.5 mg for terbutaline-but none had received intravenous $\beta$ agonist treatment. One, who subsequently received $1.25 \mathrm{mg}$ nebulised salbutamol, had been given intravenous aminophylline. Fifteen patients had had systemic corticosteroid treatment (either oral prednisolone or intravenous hydrocortisone) within six hours of admission.

Two female patients, aged 18 and 34 years, had to be withdrawn from the study immediately after receiving treatment because of clinical deterioration, and they were excluded from subsequent analysis. The remaining 30 patients (nine male and 21 female) were randomly allocated to the three dosage groups, 10 to each group. There were no significant differences between the groups with respect to age, initial $\mathrm{FEV}_{1}, \mathrm{FVC}, \mathrm{PaO}_{2}$, or pulse rate (table 1). Two of these 30 patients had to be withdrawn at a later stage of the trial. One woman became distressed 30 minutes after receiving 1.25 mg of salbutamol. Her $\mathrm{PaO}_{2}$ had risen from $8.2 \mathrm{kPa}$ $(61.5 \mathrm{~mm} \mathrm{Hg})$ before the study to $8.7 \mathrm{kPa}(65.3 \mathrm{~mm}$ $\mathrm{Hg}$ ) at 15 minutes, but her $\mathrm{FEV}_{1}$ at 30 minutes had remained unchanged at $0.4 \mathrm{l}$. The other patient, a 17 year old woman, presented with a $\mathrm{PaO}_{2}$ of $10.0 \mathrm{kPa}$ $(75 \mathrm{~mm} \mathrm{Hg})$, an arterial partial pressure of carbon dioxide $\left(\mathrm{PaCO}_{2}\right)$ of $2.9 \mathrm{kPa}(21.8 \mathrm{~mm} \mathrm{Hg})$ and an $\mathrm{FEV}_{1}$ of $1.1 \mathrm{l}$. She was given $2.5 \mathrm{mg}$ of salbutamol and at 15 minutes her $\mathrm{PaO}_{2}$ was $9.1 \mathrm{kPa}$ with a $\mathrm{PaCO}_{2}$ of $3.2 \mathrm{kPa}$. At 60 minutes, however, she was distressed with a $\mathrm{PaO}_{2}$ of $4.3 \mathrm{kPa},(32.3 \mathrm{~mm} \mathrm{Hg})$ a $\mathrm{PaCO}_{2}$ of $4.1 \mathrm{kPa}(31 \mathrm{~mm} \mathrm{Hg})$ and an $\mathrm{FEV}_{1}$ of $0.8 \mathrm{l}$.

The results in the 28 patients who completed the study are shown in table 2 and in figures 1 and 2 . Although in the series as a whole there was a small but significant rise in mean $\mathrm{FEV}_{1}(\mathrm{p}<0.05)$ and FVC $(p<0.001)$ and a fall in mean pulse rate $(p<$ 0.001 ), at the end of the study the differences from the pretreatment values for these measurements showed no significant differences between the three dosage groups. There was no correlation between the initial FEV, and FVC and the changes observed at two hours $(r=0.01)$. Table 3 shows that there was no change in mean $\mathrm{PaO}_{2}$ at either 15 or 60 minutes in any of the three dosage groups or in the series as a whole. Similarly, no changes were recorded in $\mathrm{PaCO}_{2}$ or hydrogen ion concentration. No relationship was observed between the changes in FVC at 20 and 60 minutes and the changes in $\mathrm{PaO}_{2}$ at 15 and 60 minutes in any of the three groups, nor was there any statistical association between the change in FVC and the change in pulse rate. The $\mathrm{FEV}_{1}$ and $\mathrm{FVC}$ responses in the 15 patients who had received systemic corticosteroids were similar to those in the patients who had not 
Table 2 Mean changes in spirometric values and pulse rate two hours after administration of nebulised salbutamol (standard deviations in parentheses)

\begin{tabular}{|c|c|c|c|c|}
\hline & \multicolumn{3}{|c|}{ Dose of salbutamol } & \multirow[t]{2}{*}{ All doses } \\
\hline & $1.25 \mathrm{mg}$ & $2.5 \mathrm{mg}$ & $5 \mathrm{mg}$ & \\
\hline $\begin{array}{l}\text { Number of patients } \\
\text { Increase in FEV } 1 \text { (1) }\end{array}$ & $\begin{array}{l}9 \\
0.3(0.5)\end{array}$ & $\begin{array}{l}9 \\
0.1(0.2)\end{array}$ & $\begin{array}{l}10 \\
0.4(0.3)\end{array}$ & \multirow{3}{*}{$\begin{array}{l}28 \\
0.2(0.4) \\
(\mathrm{p}<0.05) \\
0.4(0.5) \\
(\mathrm{p}<0.001) \\
14.7(15.8) \\
(\mathrm{p}<0.001)\end{array}$} \\
\hline Increase in FVC (1) & $0.3(0.4)$ & $0.4(0.3)$ & $0.7(0.6)$ & \\
\hline Fall in pulse rate (beats/min) & $15.3(16.7)$ & $19.3(9.4)$ & $8.5(18.9)$ & \\
\hline
\end{tabular}

$\mathrm{FEV}_{1}$ - one second forced expiratory volume; FVC—-forced vital . capacity.

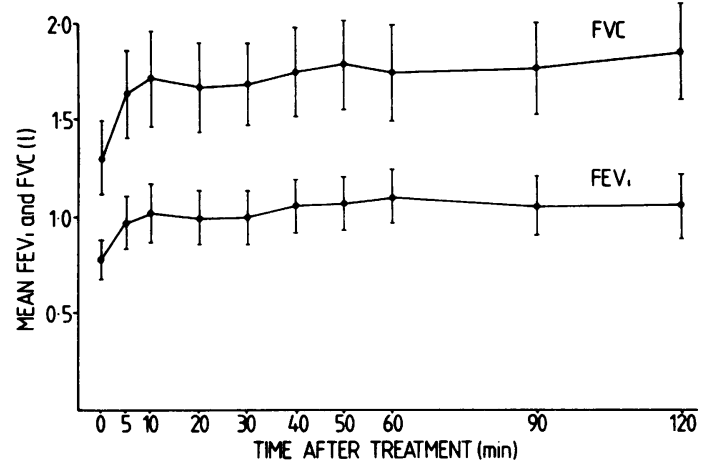

Fig 1 Means and standard errors of FEV, and forced vital capacity in 28 patients after treatment with nebulised salbutamol.

been treated with these drugs.

At the end of two hours all 28 patients were treated with high concentration oxygen, intravenous hydrocortisone, and nebulised salbutamol and made a satisfactory recovery.

\section{Discussion}

The response to bronchodilator aerosols in patients with bronchial asthma tends to decline with increas-

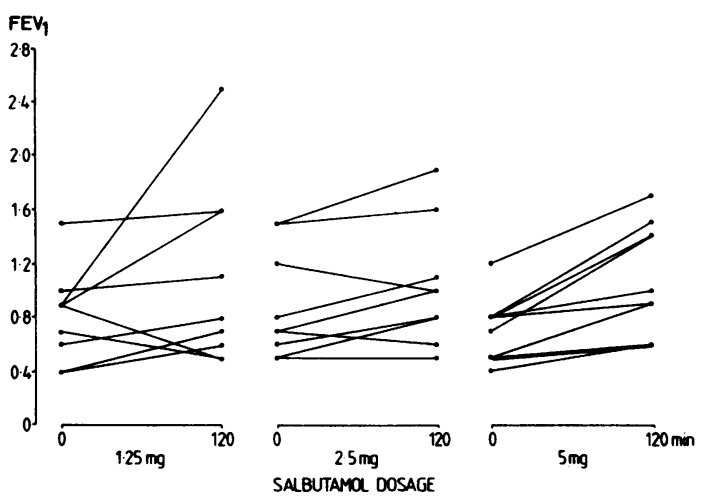

Fig 2 Individual changes in FEV, in each dosage group after treatment.

ing severity of bronchospasm, ${ }^{1}$ and large doses may then be required to relieve airflow obstruction. In this study of patients with severe acute asthma single doses of nebulised salbutamol of up to $5 \mathrm{mg}$ produced only small absolute increases in mean FEV (from 0.8 to $1.1 \mathrm{l}$ ) and in mean FVC (from 1.3 to 1.8 l), although there was a fall in mean pulse rate of 15 beats per minute. Since there was no correlation between the initial $\mathrm{FEV}_{1}$ and FVC and the increases recorded after two hours, we concluded that abso-

Table 3 Mean values for arterial oxygen tension ( $\left.\mathrm{PaO}_{2}\right) 15$ and 60 minutes after nebulised salbutamol in air (standard deviations in parentheses)

\begin{tabular}{|c|c|c|c|c|}
\hline & \multicolumn{3}{|c|}{ Dose of salbutamol } & \multirow[t]{2}{*}{ All doses } \\
\hline & $1.25 \mathrm{mg}$ & $2.5 \mathrm{mg}$ & $5 \mathrm{mg}$ & \\
\hline $\begin{array}{l}\text { Before treatment } \\
\text { Number of patients } \\
\mathrm{PaO}_{2}(\mathrm{kPa})\end{array}$ & $\stackrel{10}{8.4(0.8)}$ & $\begin{array}{l}10 \\
8.5(1.0)\end{array}$ & $\begin{array}{l}10 \\
8.4(1.0)\end{array}$ & $\begin{array}{l}30 \\
8.4(0.9)\end{array}$ \\
\hline $\begin{array}{l}15 \text { min after treatment } \\
\mathrm{Number} \text { of patients } \\
\mathrm{PaO}_{2}(\mathrm{kPa})\end{array}$ & $\begin{array}{l}10 \\
8.3(0.9)\end{array}$ & $\stackrel{10}{8.6(0.9)}$ & $\stackrel{10}{8.7(1.1)}$ & $\begin{array}{l}30 \\
8.5(0.9)\end{array}$ \\
\hline $\begin{array}{l}60 \text { min after treatment } \\
\text { Number of patients } \\
\mathrm{PaO}_{2}(\mathrm{kPa})\end{array}$ & $\begin{array}{l}9 \\
8.3(1.0)\end{array}$ & $\begin{array}{l}10 \\
8.4(1.6)\end{array}$ & $\begin{array}{l}10 \\
8.6(1.2)\end{array}$ & $\begin{array}{l}29 \\
8.4(1.3)\end{array}$ \\
\hline
\end{tabular}


lute rather than percentage increases provided a more valid expression of bronchodilator response. Although the $\mathrm{FEV}_{1}$ rose in all 10 patients given 5 $\mathrm{mg}$ nebulised salbutamol, and fell in four patients given smaller doses (fig 2), the differences in mean bronchodilator response between the three dosage groups were not statistically significant. These small changes in ventilatory function were associated with little subjective improvement and all patients remained dyspnoeic and hypoxaemic. This study therefore suggests that even the highest single dose tested, $5 \mathrm{mg}$ (equivalent to 2 Ventolin Nebules), is ineffective as an isolated therapeutic measure in severe acute asthma.

It has been reported that bronchodilator drugs, whether administered intravenously or by inhalation, are liable to increase the degree of arterial hypoxaemia ${ }^{2}$; but this study, like another recently reported, ${ }^{3}$ indicates that salbutamol nebulised in air in a single dose of up to $5 \mathrm{mg}$ does not increase hypoxaemia in severe acute asthma. The risk of aggravating hypoxaemia could conceivably be greater if repeated or larger doses of $\beta$ agonist are given. One woman in our study developed profound hypoxaemia 60 minutes after inhaling $2.5 \mathrm{mg}$ salbutamol; but her ventilatory function also deteriorated during the same period, suggesting that an increase in the severity of asthma rather than an effect of salbutamol was responsible. The bronchodilator response to single doses of salbutamol was maximal at 10 minutes (fig 1), following which there was no further improvement. This implies that if there is no response to nebulised bronchodilator treatment within that period in patients with severe acute asthma a response is unlikely to occur later, and in such cases there is an obvious need for more active therapeutic intervention.

The inhalation of large doses of $\beta_{2}$ receptor agonists from nebulisers driven by air compressors is generally believed to be both safe and effective in patients with chronic stable asthma. This study has shown, however, that during acute attacks a single dose of salbutamol of up to $5 \mathrm{mg}$ (two Ventolin Nebules) produces bronchodilator improvement that is likely to be of clinical importance in only a few patients. Larger doses may well be more effective, and can safely be given in hospital in conjunction with other treatment, including oxygen; but it has not yet been firmly established that in domiciliary practice the self administration of more than 5 $\mathrm{mg}$ of salbutamol nebulised in air does not carry an unacceptable degree of risk.

Our thanks are due to Mr W Scott, principal pharmacist, Western General Hospital, Edinburgh, for preparing the solutions of salbutamol and to $\mathrm{Dr} \mathrm{CH}$ Dash, Glaxo Pharmaceuticals Ltd, for advice and financial assistance.

\section{References}

1 Hume KM, Gandevia B. Forced expiratory volume before and after isoprenaline. Thorax 1957;12:276-8.

2 Alliot RJ, Lang BD, Rawson DRW, Leckie WJH. Effects of salbutamol and isoprenaline/phenylephrine in reversible airways obstruction. $\mathrm{Br} \mathrm{Med} J$ 1972;i:539-42.

3 Gunawardena KA, Patel B, Campbell IA, Macdonald JB, Smith AP. Oxygen as a driving gas for nebulisers: safe or dangerous? $\mathrm{Br}$ Med $J$ 1984;288:272-4. 